\title{
Synthesis and Characterization of Mesoporous Silica Nanoparticles Loaded with Repaglinide for Dissolution Enhancement
}

\author{
M. P. PATIL*, M. K. MORE, S. S. CHHAJED ${ }^{1}$, D. S. BHAMBERE AND S. J. KSHIRSAGAR
}

Department of Pharmaceutics, MET's Institute of Pharmacy, Bhujbal Knowledge City, Adgaon, Nashik (M.S) 422 003, affiliated to Savitribai Phule Pune University, Pune, India; ${ }^{1}$ Department of Pharmaceutical Chemistry, MET's Institute of Pharmacy, Bhujbal Knowledge City, Adgaon, Nashik (M.S) 422 003, affiliated to Savitribai Phule Pune University, Pune, India

Patil et al.: Mesoporous silica nanoparticles of repaglinide for dissolution enhancement

\begin{abstract}
It was evident from the literature that mesoporous silica nanoparticles can be a suitable drug carrier system because of biocompatibility, drug loading capacity; targeting ability and tunable porosity. This investigation was aimed to synthesize mesoporous silica carriers by sol-gel method using tetraethyl orthosilicate as precursor and cetyl trimethyl ammonium bromide and cetylpyrridinium chloride as a pore generating agent. Initially the effect of molar concentrations of cationic surfactants on the pore size of porous nanoparticles was studied followed by loading of repaglinide onto the surface as well as inside the pores of nanoparticles by solvent immersion method. The loaded mesoporous silica nanoparticles were evaluated for $\%$ drug loading and in vitro release. Techniques including $\mathbf{N 2}$-adsorption-desorption isotherm, $x$-ray diffractometry, scanning electron microscopy were used for characterization. The drug loading $(90.3 \pm 0.25 \%)$ was observed highest in case of nanoparticles prepared with and cetyl trimethyl ammonium bromide than that of cetylpyrridinium chloride. The drug release was found $96.5 \pm 1.15 \%$ which was more than that of pure drug and marketed formulation. The results revealed drug loading with slight decrease in crystallinity of drug in mesoporous silica nanoparticles. The particles were spherical in shape with smooth surface. In conclusion the mesoporous silica nanoparticles had shown increased dissolution because of increased surface area.
\end{abstract}

Key words: Dissolution enhancement, mesoporous silica nanoparticles, repaglinide, sol-gel method, N2 adsorption-desorption

Today majority of drugs are delivered by oral route because it offers comfort to the patient, and low manufacturing cost. To elicit pharmacological action; the drug needs to be available in the therapeutic range at the target site and to achieve this criteria drug should be soluble in sufficient amount before absorption ${ }^{[1,2]}$. It is reported that most of the drug reaching in the market as a result of fast drug discovery and development process have poor water solubility ${ }^{[3]}$, hence these drug presents poor bioavailability hence failed to achieve steady state plasma concentration ${ }^{[4]}$. Varieties of approach are used to improve the solubility/dissolution of poorly water soluble drugs. These include reduction of particle size $^{[5]}$, use of different polymorphs ${ }^{[6]}$, formation of solid dispersion ${ }^{[7]}$, complexation ${ }^{[8]}$, crystal product formation $^{[9]}$, self-emulsifying system ${ }^{[10]}$. Along with these techniques synthesis of mesoporous materials

*Address for correspondence E-mail: moreshwarppatil@gmail.com

July-August 2020 is another promising approach that can be utilized as a carrier for dissolution enhancement ${ }^{[11]}$. This has rapidly become a highly important subject area due to large surface area $(1000 \mathrm{~m} 2 / \mathrm{g})$, uniform pore size, large pore volume $(\approx 1 \mathrm{~cm} 3 / \mathrm{g})$ biocompatibility and high stability of mesoporous silica nanoparticles ${ }^{[12,13]}$. The stability due to Si-O eliminates the use of external stabilizer which is essential in liposomes, niosomes and polymeric nanoparticles. The synthesis involves hydrolysis and condensation of silica precursor followed by template removal by calcination. Hence, it This is an open access article distributed under the terms of the Creative
Commons Attribution-NonCommercial-ShareAlike 3.0 License, which
allows others to remix, tweak, and build upon the work non-commercially,
as long as the author is credited and the new creations are licensed under
the identical terms

Accepted 12 July 2020

Revised 21 June 2020

Received 17 February 2020 Indian J Pharm Sci 2020;82(4):686-691 
was decided to develop mesoporous silica nanoparticles for dissolution improvement of repaglinide; meglitinide analogue use in Type 2 diabetes mellitus. Repaglinide is Biopharmaceutics Classification System (BCS) class II drugs; have low solubility $(34.6 \mu \mathrm{g} / \mathrm{ml})$, high lipophilicity (log p 3.97) and mean absolute bioavailability is $45-65 \%^{[14,15]}$. During development due consideration was given to molar concentration of cationic surfactants i.e. cetyltrimethyl ammonium bromide (CTAB) and cetylpyridinium chloride (CPCL) as it was reported that cationic surfactant forms micellar structure suitable for growth tetraethyl orthosilicate (TEOS) based silica and removal of it creates pores in the material. Increase in the concentration of CTAB reduces the particle size ${ }^{[16]}$ which could have effect on surface area and hence on drug loading and dissolution.

\section{MATERIALS AND METHODS}

\section{Materials:}

Repaglinide was received as a gift sample from Glenmark Pharmaceuticals Ltd. Nashik. Tetraethyl orthosilicate (TEOS) was purchased from Sigma Aldrich, Bengaluru. Cetylpyridinium chloride (CPCL), cetyltrimethyl ammonium bromide (CTAB), potassium dihydrogen orthophosphate and methanol were purchased from SD Fine Chemicals Mumbai. All other chemicals and reagents used were of the analytical reagent grade.

\section{Methods:}

\section{Synthesis of mesoporous silica nanoparticles:}

Mesoporous silica nanoparticles were prepared by solgel method. As reported by Gonzalez; varying molar concentrations of CTAB and CPCL were used while molar ratio of ethanol, water, ammonium hydroxide and tetraethyl orthosilicate was kept constant ${ }^{[17]}$. The composition is shown in Table 1. Initially ethanol, water and ammonia solution $(\mathrm{NH} 4 \mathrm{OH})$ were mixed together to form silica sol. Then CTAB was added with constant stirring for $15 \mathrm{~min}$. Finally TEOS was added drop by drop under continuous stirring for $2 \mathrm{~h}$ at room temperature. The start of the reaction was confirmed by immediate formation of opaque solution. The white powder precipitated was filtered and washed with deionised water. The particles were calcined at $550^{\circ}$ for $3 \mathrm{~h}$ to remove the surfactant.

\section{Drug Loading:}

Repaglinide was loaded onto mesoporous nanoparticles
TABLE 1: COMPOSITION OF POROUS SILICA PARTICLES

\begin{tabular}{lcccc}
\hline $\begin{array}{l}\text { Concentration of } \\
\text { CTAB/CPCL }(\mathrm{mol})\end{array}$ & $\begin{array}{c}\text { Ethanol } \\
(\mathrm{mol})\end{array}$ & $\begin{array}{c}\text { Water } \\
(\mathrm{mol})\end{array}$ & $\begin{array}{c}\mathrm{NH}_{4} \mathrm{OH} \\
(\mathrm{mol})\end{array}$ & $\begin{array}{c}\text { TEOS } \\
(\mathrm{mol})\end{array}$ \\
\hline 0.1 & 20 & 45.6 & 10.4 & 1 \\
0.3 & 20 & 45.6 & 10.4 & 1 \\
0.5 & 20 & 45.6 & 10.4 & 1 \\
\hline
\end{tabular}

by solvent immersion method. In this experiment n-hexane; a nonpolar solvent was used for drug loading because polar solvent may compete for drug molecule for adsorption site. Preliminary formulation batches of mesoporous silica nanoparticles (MSNs) were developed to decide the ratio for drug loading. For drug loading; repaglinide: blank MSNs using CTAB and CPCL in ratio $1: 1$ to $1: 4$ were prepared. On the basis of drug loading it was decided to prepare the batches in ratio of 1:2. The blank MSNs and repaglinide was dispersed in $20 \mathrm{ml}$ hexane. The dispersion was stirred for $4 \mathrm{~h}$, centrifuged and the supernatant was removed. Finally mesoporous silica nanoparticles were collected and dried at room temperature for $24 \mathrm{~h}^{[18]}$.

\section{Characterization of blank and repaglinide loaded nanoparticles:}

Surface area pore size and pore volume analysis. The surface areas of different batches of MSNs were evaluated by nitrogen adsorption- desorption isotherm measurements using surface area analyzer (Quantachrome Instruments, India; V11.05) at $-196^{\circ}$. The samples were degassed at $150^{\circ}$ for $6 \mathrm{~h}$ before analysis. The surface was determined using BraunerEmmett-Teller (BET) theory. The pore volume and pore size distribution were derived from the adsorption branches of the isotherms using Barrett-Joyner-Halenda (BJH/DH) method ${ }^{[19]}$.

\section{PXRD analysis:}

The x-ray powder diffraction pattern of repaglinide; MSNs prepared by using CTAB and CPCL were recorded using on x-ray diffractometer (Bruker D8 Advance, India) using Ni-filtered, and $\mathrm{CuK} \alpha$ radiation operated at voltage of $35 \mathrm{Kv}$ and current of $25 \mathrm{~mA}$. The scanning rate employed was 10 per minute over 50 to 500 diffraction angle $(2 \theta)$ range $^{[20]}$.

\section{SEM study:}

The shape and surface morphology of the particles prepared with CTAB and CPCL was examined using a scanning electron microscope (JEOL/JEM 2100, Japan). The spheres were vacuum dried, coated with a 
thin gold-palladium layer with a sputter coater unit and observed microscopically at an accelerating voltage of $10 \mathrm{Kv}$.

\section{\% drug loading:}

Amount of repaglinide loaded on mesoporous particles were determined by suspending particles equivalent to $10 \mathrm{mg}$ of repaglinide in $100 \mathrm{ml}$ of phosphate buffer $(\mathrm{pH} \mathrm{5)}$; stirred continuously on magnetic stirring for $24 \mathrm{~h}$ at room temperature. After stirring; the solution was filtered through cellulose acetate membrane $(0.22 \mu \mathrm{m})$. The amount of drug in the filtrate was analyzed using UV spectrophotometer (UV 1801, Shimadzu Co, Japan) at $240 \mathrm{~nm}^{[21]}$.

\section{Dissolution study:}

The in vitro dissolution was determined using USP Type II dissolution test apparatus (TDT-08, Electrolab India). Repaglinide and its loaded silica nanoparticles (equivalent to $10 \mathrm{mg}$ of repaglinide) were filled in empty capsule shells and put into the vessel containing phosphate buffer $(\mathrm{pH}$ 5) which was maintained at $37^{\circ} \pm 0.5^{\circ}$. The paddle rotation speed was kept at $75 \mathrm{rpm}$ and the study was conducted for one hr. Aliquots of $10 \mathrm{ml}$ were withdrawn at predetermined time intervals and fresh volume of dissolution medium was added to maintain sink condition ${ }^{[22]}$. The samples were analyzed spectrophotometrically at $240 \mathrm{~nm}$. The experiments were performed in triplicate for each batch.

\section{RESULTS AND DISCUSSION}

The drug loading particularly in case of mesoporous particles is based on adsorption. The amount of drug loaded in the MSNs prepared by using CTAB and CPCL were $90.3 \%$ and $60.8 \%$ respectively. The highest drug loading found in case of CTAB may be due to larger surface area and pore volume than that of CPCL. This was confirmed by $\mathrm{N} 2$ adsorption-desorption technique. One more reason for high loading of repaglinide was probably an interaction of drug with surface silanol i.e. $-\mathrm{OH}$ group particularly through functional group -O- (ether); - $\mathrm{COOH}$ (acid) and -NH. Probable H-bond would forms between electrons deficient hydrogen of silanol with carboxyl carboxyl oxygen, oxygen of ether is shown in fig. 1.

It was further evident from FTIR spectrum of drug and drug loaded porous particles that $\mathrm{C}=\mathrm{O}$ stretching in pure drug and drug loaded on mesoporous silica nanoparticles differs i.e. 1712 and $1708 \mathrm{~cm}-1$ respectively which may be due to weakening of double bond character of $\mathrm{C}=\mathrm{O}$ functional group. Further $-\mathrm{OH}$ stretching in loaded porous particles would not able to resolve $-\mathrm{H}$ bond interaction as bands in the region 3000 to $3500 \mathrm{~cm}-1$ are overlapped. The overall interaction of functional groups of repaglinide and surface silanol group is depicted in fig. 2. The FTIR spectrums are presented in fig. 3. Nitrogen adsorption and desorption isotherms of blank as well as repaglinide loaded particles are shown in fig. 4 and fig. 5. As per the IUPAC classification; all samples were classified as Type IV isotherm showing hysteresis loop; initial loop is of monolayer or multilayer adsorption while second loop is of desorption. CTAB and CPCL particles showed N2 isotherm wherein the amount of $\mathrm{N} 2$ adsorption increases above $\mathrm{P} / \mathrm{P} 0=0.2$. This suggested $\mathrm{N} 2$ condensation within the pores and confirms the presence of mesopores. Desorption was one step indicating the open mesopores. Particles prepared using CTAB exhibited adsorption isotherm at higher relative pressure which corresponds to condensation of $\mathrm{N} 2$ in the interparticulate voids and confirms small size. The pore size distribution was determined by BJH model. Surface area of the mesoporous nanoparticles was observed in the range from 13.65 to $28.13 \mathrm{~m}^{2} / \mathrm{g}$. The

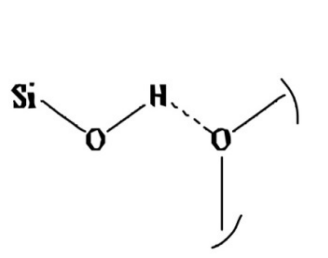

(A)

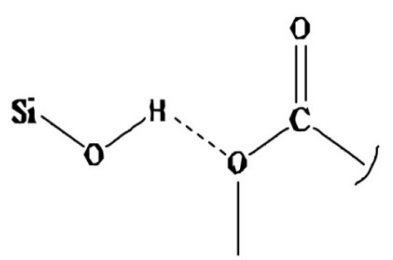

(B)
Fig. 1: Interaction of $H$ bond between silanol and ether of drug (A) and $\mathrm{H}$ Bond between silanol and carboxyl group of drug (B)

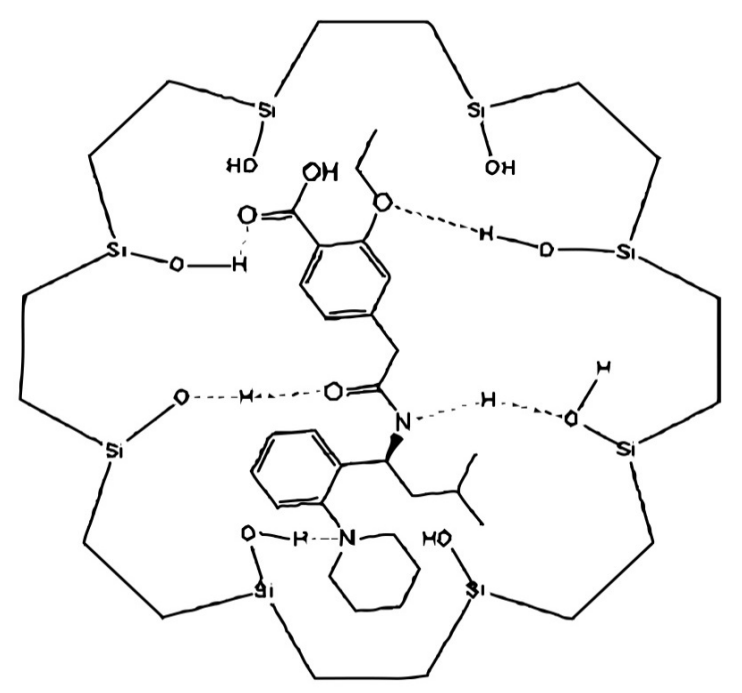

Fig. 2: Hypothetical diagram depicting interactions of repaglinide with surface silanol 


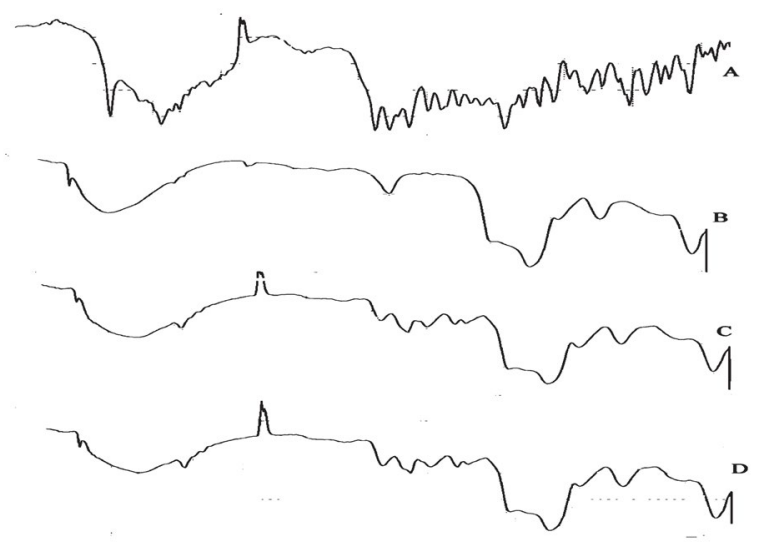

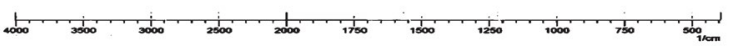

Fig. 3: FTIR spectrum of repaglinide (A), blank (B), repaglinideCTAB (C) and repaglinide-CPCL (D) porous particles
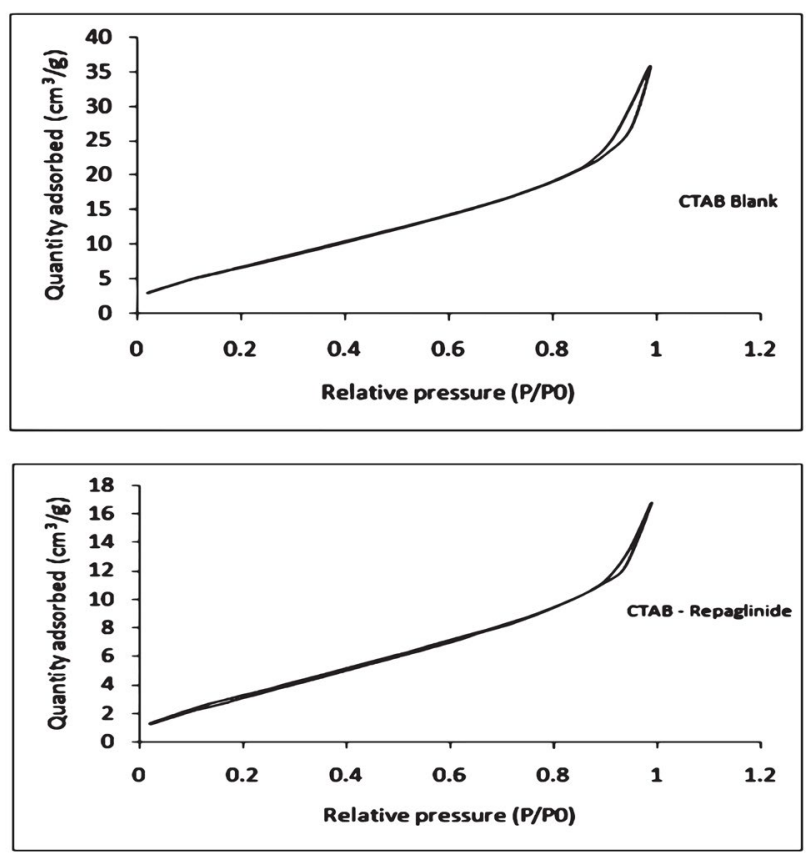

Fig. 4: $\mathrm{N}_{2}$ adsorption-desorption isotherm of CTAB blank and drug loaded porous particle

surface area was reduced in case of repaglinide loaded particles; this confirms the adsorption of drug on the surface. Also the pore size is increased in case of drug loaded particles. This may happens due to incorporation of drug inside the pores leads to expansion of pore size particularly in case of CTAB. But this was not observed with CPCL. The pore volume was reduced because of the space inside the pores was occupied by drug ${ }^{[17,22-25]}$. The results of surface area; pore size and pore volume are given in Table 2. The powder X-ray diffraction pattern of the repaglinide confirms that the drug is available in crystalline form. It showed characteristic diffraction peaks at $2 \theta$ angle of $7.6,10.14,13.25,13.84$, $16.73,17.60,20.37$ and 23.08 (fig. 6A). However, there were no crystal diffraction patterns of repaglinide in the nanoparticles (fig. 6B). Hence; this section concludes by examining the diffractogram of nanoparticles that the drug was present in amorphous form ${ }^{[21]}$.

Surface morphology of repaglinide loaded mesoporous silica nanoparticles are shown in fig. 7. It has been observed from the photomicrographs that the particles are spherical in shape with smooth surface although they have varying particle size i.e. polydispersity ${ }^{[26]}$.

TABLE 2: RESULTS OF PORE SIZE, PORE VOLUME AND SURFACE AREA

\begin{tabular}{lccc}
\hline $\begin{array}{l}\text { Porous nanoparticles } \\
\text { batch }\end{array}$ & $\begin{array}{c}\text { Surface } \\
\text { area } \\
\left(\mathrm{m}^{2} / \mathrm{g}\right)\end{array}$ & $\begin{array}{c}\text { Pore size } \\
(\mathbf{n m})\end{array}$ & $\begin{array}{c}\text { Pore } \\
\text { volume } \\
\left(\mathrm{cm}^{3} / \mathbf{g}\right)\end{array}$ \\
\hline CTAB MSN (Blank) & 28.137 & 1.557 & 0.053 \\
CTAB (Drug loaded) & 14.682 & 2.404 & 0.030 \\
CPCL MSN (Blank) & 24.245 & 2.144 & 0.033 \\
CPCL (Drug loaded) & 13.651 & 1.555 & 0.029 \\
\hline
\end{tabular}
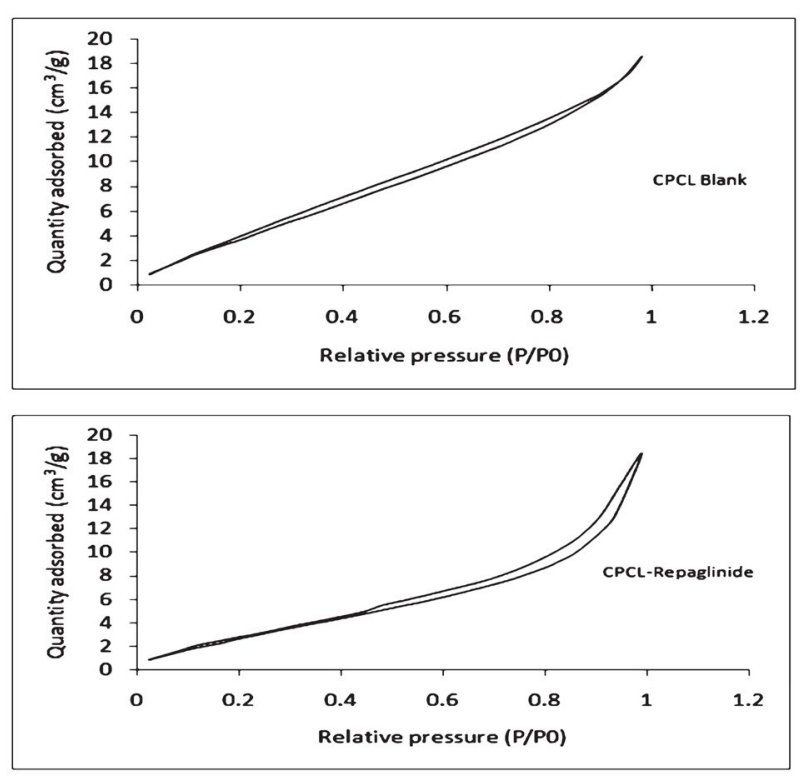

Fig. 5: $\mathrm{N}_{2}$ adsorption-desorption isotherm of CPCL blank and drug loaded porous particle
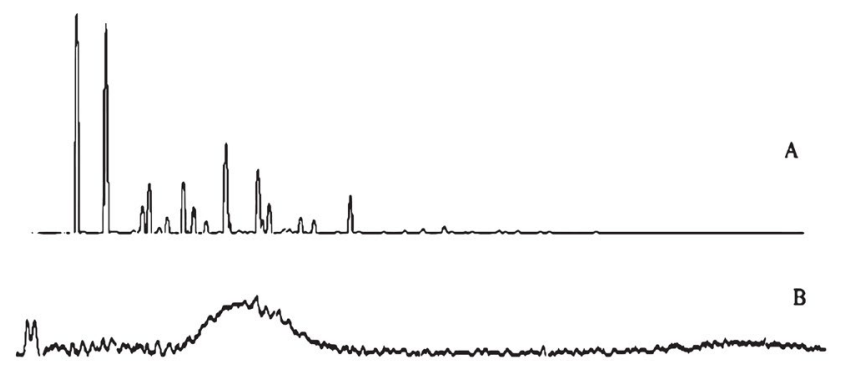

Fig. 6: X-ray diffraction pattern of repaglinide (A) and its MSNs with CTAB (B) 


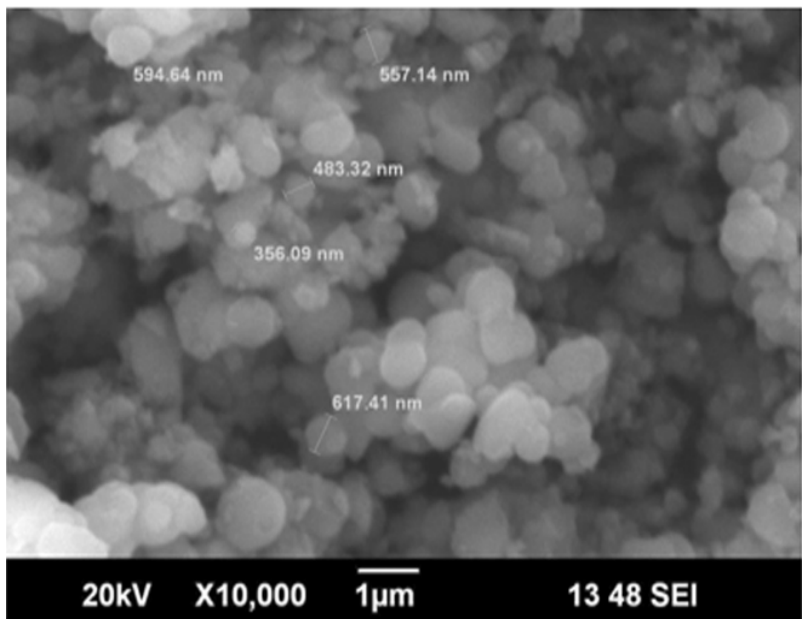

Fig. 7: SEM photomicrographs of MSNs prepared with CTAB

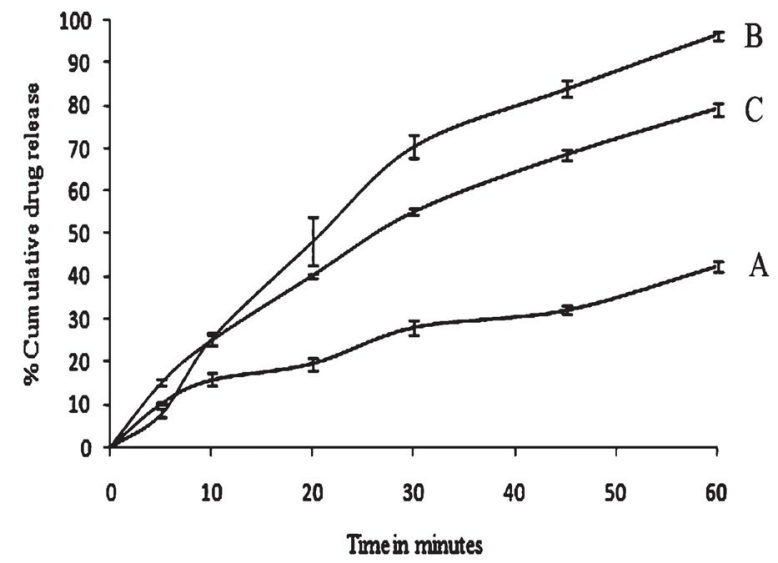

Fig. 8: Comparison of dissolution profiles: repaglinide (A), MSNs with CTAB (B) and marketed formulation (C)

The particle size observed was ranged up to $617.41 \mathrm{~nm}$.

The comparison of dissolution profiles of repaglinide, silica particles loaded with repaglinide and marketed formulation are shown in fig. 8. The study was conducted for $1 \mathrm{~h}$; repaglinide alone had shown 42.56 $\%$ release. In case of CTAB-MSN formulation; 96.5 $\%$ of drug was liberated from the formulation while conventional marketed tablet formulation had shown $79.25 \%$ drug release. The enhancement of dissolution velocity was observed in silica nanoparticles as compare to pure drug and marketed formulation. The mechanism for improved dissolution predicted is increased surface area provided by the mesoporous silica nanoparticles; reduction of the particle size of the particles and drug and availability of drug in amorphous form ${ }^{[27,28]}$.

This research work demonstrates the synthesis of mesoporous silica nanoparticles and one of their applications in the dissolution enhancement of poorly water soluble drug; repaglinide. We had developed porous silica particles which provided larger surface area for drug and acts as a nano-container. The characterization of silica particles confirmed that the drug was found adsorbed on the surface as well as inside the pores. Dissolution of repaglinide was increased as a result of increased surface area, pores size, pore volume because of use of mesoporous silica nanoparticles as a carrier and conversion of drug from crystalline to amorphous state. This investigation will helps in designing of rapid and/or prolonged release formulation for oral administration

\section{Acknowledgements:}

The authors are thankful to Trustees, MET's Institute of Pharmacy, Bhujbal Knowledge City, Nashik for providing the research facilities. They are also thankful to Glenmark Pharmaceuticals Ltd., Mumbai for providing the sample of repaglinide.

\section{Conflict of Interests:}

The authors declare that they have no conflict of interest.

\section{REFERENCES}

1. Maleki A, Kettiger H, Schoubben A, Rosenholm J, Ambrogi V, Hamidi M. Mesoporous silica materials: from physicochemical properties to enhanced dissolution of poorly watersoluble drugs. J Control Release 2017;262:329-47.

2. Kawabata Y, Wada, K, Nakatani M, Yamada S, Onoue S. Formulation design for poorly water-soluble drugs based on biopharmaceutics classification system: basic approaches and practical applications. Int J Pharm 2011;420:1-10.

3. Loftsson T, Brewster M. Pharmaceutical applications of cyclodextrins: basic science and product development. J Pharm Pharmacol 2010;62:1607-21.

4. Sharma M, Sharma R, Jain D. Nanotechnology based approaches for enhancing oral bioavailability of poorly water soluble antihypertensive drugs. Scientifica 2016;1-11.

5. Khadka P, Ro J, Kim H, Kim I, Kim J, Kim H, et al. Pharmaceutical particle technologies: an approach to improve drug solubility, dissolution and bioavailability. Asian J Pharm Sci 2014;9:304-16.

6. Censi R, Martino P. Polymorph impact on the bioavailability and stability of poorly soluble drugs. Molecules 2015;20:1875976.

7. Serajuddin A. Solid dispersion of poorly water-soluble drugs: Early promises, subsequent problems, and recent breakthroughs. J Pharm Sci 1999;88:1058-66.

8. Pattnaik S, Nandi S, Sahoo R, Nanda A, Swain R, Das S, et al. Budesonide-cyclodextrin in hydrogel system: impact of quaternary surfactant on in vitro-in vivo assessment of mucosal drug delivery. Rev Chim 2020;71:332-45.

9. Satapathy B. S, Patel A, Sahoo R, Mallick S. Crystal products of lamotrigine-citric acid for improvement of in vitro drug release in simulated gastric fluid. J Serb Chem Soc 2020;85:112.

10. Gursoy R, Benita S. Self-emulsifying drug delivery systems (SEDDS) for improved oral delivery of lipophilic drugs. Biomed Pharmacother 2004;58:173-82. 
11. Merisko-Liversidge E, Liversidge G. Drug nanoparticles: formulating poorly water-soluble compounds. Toxicol Pathol 2008;36,43-48.

12. Beck J, Vartuli J, Roth W, Leonowicz M, Kresge C, Schmitt K, et al. A new family of mesoporous molecular sieves prepared with liquid crystal templates. J Am Chem Soc 1992;114:1083443.

13. Al-Kady A, Gaber M, Hussein M, Ebeid E. Nanostructureloaded mesoporous silica for controlled release of coumarin derivatives: a novel testing of the hyperthermia effect. Eur J Pharm Biopharm 2011;77:66-74.

14. Mortazavi Y, Ghoreishi S. Synthesis of mesoporous silica and modified as a drug delivery system of ibuprofen. J Nanostruct 2019;6:86-89.

15. Mandic Z, Gabelica V. Ionization, lipophilicity and solubility properties of repaglinide. J Pharmceut Biomed 2006;41:86671.

16. Purwaningsih H, Ervianto Y, Pratiwi V, Susant D, Purniawan A. Effect of cetyl trimethyl ammonium bromide as template of mesoporous silica mcm-41 from rice husk by sol-gel method. IOP Conf. Series: Mat Sci Eng 2019;515:1-9.

17. Hatorp V, Oliver S, Su C. Bioavailability of repaglinide, a novel anti-diabetic agent, administered orally in tablet or solution form or intravenously in healthy male volunteers. Int J Clin Pharm Th 1998;36:636-41.

18. Vazquez N, Gonzalez Z, Ferrari B, Castro Y. Synthesis of mesoporous silica nanoparticles by sol-gel as nanocontainer for future drug delivery applications. Bol Soc Esp Cerám V 2017;56:139-45.

19. McCarthy C, Ahern R, Dontireddy R, Ryan K, Crean A.
Mesoporous silica formulation strategies for drug dissolution enhancement: a review. Expert Opin Drug Del 2016;13:93108.

20. Huang X, Young N, Townley H. Characterization and comparison of mesoporous silica particles for optimized drug delivery. Nanomater Nanotechno 2014;4:1-15.

21. Zhu Z, Yang T, Zhao Y, Gao N, Leng D, Ding P. A simple method to improve the dissolution of repaglinide and exploration of its mechanism. Asian J Pharm Sci 2014;9:218-25.

22. Samadi-Maybodi A, Vahid A. Synthesis of mesoporous silica nanoparticles by means of hydrogel. Int Nano Lett 2013;3:1-3.

23. Zukal A, Siklova H, Cejka J, Thommes M. Preparation of MCM-41 silica using the cationic surfactant blend. Adsorption 2007;13:247-56.

24. Swar S, Makova V, Stibor I. Effectiveness of diverse mesoporous silica nanoparticles as potent vehicles for the drug L-dopa. Materials 2019;12:1-15.

25. Ghaffari A, Tehrani M, Husain S, Anbia M., Aberoomand Azhar P. Adsorption of cholorophenols from aqueous solution over amino modified ordered nanoporous silica materials. J Nanostruct Chem 2014; 4:1-10.

26. Moodley T, Snigh M. Polymeric mesoporous silica nanoparticles for enhanced delivery of 5-fluorouracil in vitro. Pharmaceutics 2019;11:288.

27. Patel M, Pandya N, Bhaskar V. Preparation, characterization and in vitro evaluation of repaglinide binary solid dispersions with hydrophilic polymers. Int J Drug Dev Res 2011;3:107-17.

28. Gadadare R, Mandpe L, Pokharkar V. Ultra rapidly dissolving repaglinide nanosized crystals prepared via bottom-up and top-down approach: influence of food on pharmacokinetics behavior. AAPS Pharm Sci Tech 2015;16:787-99. 